\title{
Comparison between Azithromycin and Cephalexin for Preventing Infection after Cesarean Section in Obese Patient
}

\author{
Maryam Azizi', Minoo Rajaei', Maryam Abbasian ${ }^{2 *}$, Amin Ghanbarnejad ${ }^{3}$, Aida Najafian', \\ Maryam Iranfar ${ }^{2}$ \\ ${ }^{1}$ Obstetrics and Gynecology Department, Hormozgan Fertility and Infertility Research Center, Hormozgan \\ University of Medical Sciences, Bandarabbas, Iran \\ ${ }^{2}$ Student Research Committee, Hormozgan University of Medical Sciences, Bandar Abbas, Iran \\ ${ }^{3}$ Research Center for Social Determinants in Health Promotion, Department of Research and Technology, \\ School of Health, Hormozgan University of Medical Sciences, Bandarabbas, Iran \\ Email: ${ }^{*}$ maryamabbasian@yahoo.com
}

Received 16 August 2014; revised 15 September 2014; accepted 14 October 2014

Copyright $@ 2014$ by authors and Scientific Research Publishing Inc.

This work is licensed under the Creative Commons Attribution International License (CC BY).

http://creativecommons.org/licenses/by/4.0/

(c) (i) Open Access

\section{Abstract}

Introduction: Postcesarean infection can cause maternal mortality and morbidity. Use of prophylactic antibiotics could decrease surgical site infection. Despite using prophylactic antibiotics in obese women, compared to normal weighted women the rate of wound infection is higher in this group. The aim of this study is to compare prophylactic effect of azithromycin and cephalexin on febrile morbidity and postcesarean infection in women with BMI > 30. Methods and Materials: This randomized controlled double blind clinical trial was done on 231 women with BMI > 30 who underwent elective cesarean section. Patients were randomly divided to intervention and control groups. Keflin 2 gr IV was administered $0.5 \mathrm{hr}$ before surgery for both intervention and control groups. Cefalexin (placebo) every $6 \mathrm{hr}$ and azythromycin (placebo) every $12 \mathrm{hr}$ for control group and cephalexin $500 \mathrm{mg}$ every $6 \mathrm{hr}$ and azithromycin $250 \mathrm{mg}$ every $12 \mathrm{hr}$ for intervention group were administered for 48 hrs. Patients were under observation till 1 month after surgery. Fever, wound infection, endometritis and hospitalization were compared between two groups with SPSS v. 18. Results: A total of 231 patients $113(48.9 \%)$ were enrolled in intervention group and 118 $(51.1 \%)$ in control group with mean age of $(28.53 \pm 5.51)$ recruited. BMI distribution did not differ in the two groups. Hospitalization in control group was significantly higher than that in intervention group $(2.58 \pm 0.99)$ vs $(2.11 \pm 0.45)$ ( $P$ value $<0.001)$. BMI in intervention group with and without fever was $(34.62 \pm 2.64)$ and $(30.89 \pm 2.80)$, respectively $(P$ value $<0.001)$. In control group, BMI in patients with and without fever was $(38.60 \pm 2.80)$ and $(31.29 \pm 1.28)$, respectively

${ }^{*}$ Corresponding author.

How to cite this paper: Azizi, M., Rajaei, M., Abbasian, M., Ghanbarnejad, A., Najafian, A. and Iranfar, M. (2014) Comparison between Azithromycin and Cephalexin for Preventing Infection after Cesarean Section in Obese Patient. International Journal of Clinical Medicine, 5, 1214-1220. http://dx.doi.org/10.4236/ijcm.2014.519155 
( $P$ value $=0.001)$. Fever and endometritis simultaneously was seen in $3(2.7 \%)$ of intervention group and $8(6.8 \%)$ of control group. In interventions $3(2.7 \%)$ had fever but no endometritis and $2(1.8 \%)$ had endometritis but no fever $(P<0.001)$. In control group, $23(19.5 \%)$ patients had fever but no endometritis and $4(3.4 \%)$ patients had endometritis but no fever $(P$ value $<0.001)$. Febrile patients in control group $31(26.3 \%)$ were significantly more than those in intervention group 6 (5.3\%) (P value < 0.001). Discussion: Administration of prophylactic azithromycin and cephalexin resulted in a decrease in febrile morbidity and length of hospital stay and is recommended. BMI of patients with fever was significantly higher in both intervention and control groups compared to those who didn't experience fever. Postcesarean endometritis wasn't significantly different in two groups. Postcesarean wound infection wasn't seen in any group.

\section{Keywords}

\section{Antibiotic, Infection, Cesarean, Obesity, Fever}

\section{Introduction}

Postcesarean infection is one of the most common causes of mortality and morbidity after cesarean and could be a cause of maternal death. Nosocomial infections are one of the causes of prolonged admission of patients and increase burden of treatment on families and societies [1]. Patients with infected with post-operational infection are $60 \%$ more likely to be admitted in intensive care unit ward, and 5 times more likely to get re-admitted. Amount of mortality rate in these patients is twice more than those who don't get post-op infection. Many factors including type of infecting micro-organisms, level of their virulence, host's defense mechanisms, appropriate treatments and correct surgical technique are effective on post-partum infection [2]. Unfortunately by use of all correct and sterile techniques, mainly due to increase in methicillin resistant Staphylococcus aureus (MRSA) and Candida spp., post surgical cesarean infections are still a big problem worldwide [3]. Use of prophylactic antibiotics reduces surgical site infection [4]-[7], and evidence according to international guidelines proposes that antibiotic prophylaxis is used prior to surgical procedure [5]-[8], but cesarean section is another story, because antibiotic administration before incision and fetal access to the antibiotics may cause adverse fetal effects. It's nearly been 30 years that standard precaution for post-cesarean infection is administration of narrow spectrum prophylactic antibiotics after delivery and clamping the umbilical cord [7] [9]. Rate of cesarean section in United States has increased from 20.7\% in 1996 to 31.1\% in 2006 and it is estimated that till next decade this rate would increase up to 50\% [10] [11]. Increase in total rate of cesarean section is indicative of primary cesarean section and repeated cesarean section. Recent evidence shows that primary cesareans are increasing in absence of obstetric indications [12]. If this trend increases till 2020, annually $50 \%$ of 4 million births would be born by cesarean section, hence burden of infection increases [5] [6] [10]. On the other hand obesity is being increased and one third of women in reproductive age are obese; this obesity is a cause of complications and especially cesarean [13]. Despite the use of antibiotic profile in obese women wound infection is higher compared to women with normal weight [14]-[17]. Serum antibiotic level depends on tissue diffusion and local blood flow and type of tissue in different people [18]. Obesity causes increased tissue diffusion and dilution of primary dosage of the antibiotic in comparison with individuals with normal weight [19] [20]. On the other hand because of scarce amount of vessels in adipose tissue, local blood flow is also decreased, so in obese women tissue perfusion is very weak and all of these conditions decrease antibiotic diffusion in tissues [21] [22]. Prophylactic antibiotic should cover the probable microbial spectrum which may cause infection in the site of the incision. Antibiotic in the area of incision should have minimal inhibitory concentration for the most abundant microbial pathogen and enough therapeutic concentration of antimicrobial during the operation [23]. Standard prophylactic antibiotic in all weights for women undergoing cesarean section is $2 \mathrm{~g}$ intravenous (IV) cefazolin before surgery [24]. Previous studies show that use of long acting broad spectrum antibiotic for 48 hours inhibits growth of microbes and decreases post-cesarean infection in susceptible obese women [25].

Cefalotin sodium with a trade name of keflin, is a $1^{\text {st }}$ generation cephalosporin which is administered intravenously; its antimicrobial spectrum is similar to other first generation cephalosporins such as cefazolin and cephalexin. Cefazolin is usually used for treatment of skin infections and is effective for staphylococci, and gram 
positive streptococci. These microbes are usually present as human skin normal flora. Cephalexin has antimicrobial activity against streptococcus beta hemolyticus, staphylococcus (coagulase positive, coagulase negative, Escherichia coli, Proteus mirabilis, klebsiella, and hemophilus influenza) [26]. In this study prophylactic effect of azithromycin and cephalexin accompanied with a first generation cephalosporin (keflin) is compared with keflin alone in preventing fever and infection after cesarean in women with BMI > 30. Endometriosis is inflammation of endometrium which may sometimes involve myometrium also. Wound infection is a mechanism in which bacteria or pathogenic microorganisms colonize in the wound and cause delay in wound healing. Body temperature of more than 38 degrees centigrade orally is regarded as fever, and women who have undergone cesarean section 2 separate temperature readings 6 hours apart within 10 days after delivery (except first 24 hours of cesarean) is regarded as fever.

\section{Methodology}

This randomized double blind controlled trial was carried out on elective cesarean section patients in Shariati Hospital in a seaport in south of Iran.

Study was carried out from 21 August 2011 till 21 August 2012.

Demographic data including maternal age, gestational age, no of gravidity, body mass index (BMI), wound infection, fever, endometritis, duration of admission, re-admission were entered in a check list.

This double blind clinical trial was performed on 231 patients who had undergone elective cesarean section.

Inclusion criteria included: 1) maternal age more than 14 years old; 2) BMI > 30; 3) gestational age $\geq 37$ weeks.

Exclusion criteria included: 1) pregnant women with a positive history of diabetes, hypertension, collagen vascular diseases; 2) rupture of membranes; 3) antibiotic therapy prior to cesarean section; 4) twin pregnancy; 5) blood transfusion during and after cesarean section; and finally 6) administration of corticosteroids; 7) in cooperative patient; 8) complications including wound complications (dehiscence, hematoma or seroma).

Methodology: After measurement of height and weight, body mass index was calculated. Randomization was done using block randomization with four blocks, and the patients were divided in intervention and control groups. In both groups operation technique and duration and prior cesareans and even type of incision was not done by one surgeon, but in this study the surgical team were equivalent. Thirty minutes prior to operation $2 \mathrm{gr}$ keflin was administered for control group and after operation $500 \mathrm{mg}$ cephalexin as a placebo every 6hours and $250 \mathrm{mg}$ azithromycin as a placebo every 12 hours for $48 \mathrm{hrs}$.

In intervention group $2 \mathrm{~g}$ keflin was administered intravenously $0.5 \mathrm{hr}$ before surgery and for 48 hours 500 mg cephalexin every 6 hours and $250 \mathrm{mg}$ azithromycin every $12 \mathrm{hrs}$ was prescribed for them.

The patients, obstetrician, nursing staff, and the gynecologist who followed up the patients were blinded. The patients were admitted for 48 hours in hospital and till one month after cesarean section well followed as outpatients for occurrence of fever, wound infection, and signs of endomteritis. The patients were referred to outpatient clinic if any fever occurred and were revisited again at the end of the month. Endometritits was diagnosed in patients who had no source of fever according to laboratory findings and clinical findings had criteria of endometritis. The data of two groups were analysed by SPSS version 18 .

\section{Ethical Issues}

According to Helsinki Declaration on ethical issues of studies on humans, the data were recorded confidential, and the details of the confidentiality of the data were described to the patients. An informed written consent was obtained from the patients and they were ensured they can refrain from the study any time they wanted. No additional charges were made for the patients. Azithromycin and cephalexin were in class B of FDA division of medications and have no adverse effects on fetus and mother and many prophylactic studies have shown no adverse effects have been shown when these drugs are used prophylactically.

\section{Statistical Analysis}

Data were collected in a checklist, and analysed by SPSS 18 for windows. Average of maternal age, gestational age, gravidity, duration of admission, and re-admission, were calculated, percentile of fever, infection, endometritis, in intervention and control group was calculated by descriptive analysis. Quantitative parameters were 
analysed by average and standard deviation. Duration of admission, re admission in both groups, BMI, maternal age, gestational age between two groups, independent t-test was used. Also to compare fever, wound infection, and endometritis chi-square test was used.

\section{Results}

In this double blind trial 231 women were selected for elective cesarean section, of which 113 (48.9\%) were included in intervention group and 118 (51.1\%) in control group. Mean age of the study participants was $28.53 \pm$ 5.51 years. Youngest patient was 17 years old and the oldest was 42 years old. Mean age of the intervention group was $28.94 \pm 5.59$ years and $28.14 \pm 5.43$ years in control group. Mean number of gravidity in intervention group was $2.77 \pm 1.24$ and $2.57 \pm 1.22$ in control group. Mean gestational age in intervention group was $37.95 \pm$ 0.65 and $38.07 \pm$ in 0.70 weeks in control group. Previous cesareans in intervention groups were $0.97 \pm 1.35$ and in control group $0.87 \pm 1.27$. BMI of the intervention group was $31.67+2.15$ and BMI of control group was $31.87+2.36$. Age, gestational age, BMI, gravidity, previous cesareans had no significant difference between intervention and control groups $(\mathrm{P}>0.05)$ (Table 1$)$. Control group were admitted for $2.58 \pm 0.99$ days and the intervention group were admitted for $2.11 \pm 0.45$ days which was statistically significant $(\mathrm{P}<0.001)($ Table 1$)$. Six patients of interventiongroup (5.3\%) had post-op fever, while 31 patients (26.3\%) of control group had post-op fever and this difference is statistically significant $(\mathrm{P}<0.001)$ (Table 2). In intervention group, mean age of febrile patients was $28.87 \pm 5.01$ years and $27.87 \pm 5.57$ years in afebrile patients $(\mathrm{P}=0.36)$. Mean age of febrile and a febrile patients in control group was $33.5 \pm 4.32$ years and $28.68 \pm 5.56$ years respectively which had no significant difference $(\mathrm{P}=0.35)$. Mean gestational age of the febrile patients in intervention group was $37.97 \pm 0.60$ weeks while it was $38.1 \pm 97$ weeks in afebrile patients that did not differ significantly $(P=0.12)$. Mean age of febrile and afebrile patients in control group was $37.83 \pm 0.40$ and $37.95 \pm 0.66$ respectively which also had no significant difference $(\mathrm{P}=0.54)$. Body mass index of febrile and afebrile patients was $34.62 \pm 2.64$ $\mathrm{kg} / \mathrm{m}^{2}$ and $30.89 \pm 1.21 \mathrm{~kg} / \mathrm{m}^{2}$ respectively in intervention group $(\mathrm{P}<0.001)$. Body mass index of febrile and afebrile patients was $38.6 \pm 2.8 \mathrm{~kg} / \mathrm{m}^{2}$ and $31.29 \pm 1.28 \mathrm{~kg} / \mathrm{m}^{2}$ respectively in control group $(\mathrm{P}<0.001)$. Endometritis after cesarean was seen in 5 (4.4\%) of the intervention and 12 (10.2\%) of control which had no significant difference $(\mathrm{P}=0.95)$. Concomitant fever and endometritis was seen in $3(2.7 \%)$ of intervention and $8(6.8 \%)$ of controls. Three of the intervention (2.7\%) had fever but didn't suffer from endometritis, and 2 of the intervention (1.8\%) had endometritis but were aferile. Overall febrile patients without endometritis in control group

Table 1. Comparison age, gravidity, previous cesareans, gestational age body mass index and duration of admission in intervention and control.

\begin{tabular}{|c|c|c|c|c|c|c|c|}
\hline & & No & Average & Maximum & Minimum & $\begin{array}{l}\text { Standard } \\
\text { deviation }\end{array}$ & $P$ value \\
\hline Age & Intervention & 113 & 28.94 & 40 & 17 & 5.59 & 0.27 \\
\hline Age & Control & 118 & 28.14 & 42 & 18 & 5.43 & \\
\hline Gravidity & Intervention & 113 & 2.77 & 6 & 1 & 1.24 & 0.21 \\
\hline Gravidity & Control & 118 & 2.57 & 8 & 1 & 1.22 & \\
\hline Previous cesarean & Intervention & 113 & 1.35 & 5 & 0 & 0.97 & 0.29 \\
\hline Previous cesarean & Control & 118 & 1.24 & 4 & 0 & 0.87 & \\
\hline Gestational age & Intervention & 113 & 37.95 & 40 & 37 & 0.65 & 0.17 \\
\hline Gestational age & Control & 118 & 38.07 & 40 & 36 & 0.7 & \\
\hline BMI & Intervention & 113 & 31.67 & 42.9 & 30 & 2.15 & 0.50 \\
\hline BMI & Control & 118 & 31.87 & 41.7 & 30 & 2.36 & \\
\hline Duration of admission & Intervention & 113 & 11.2 & 4 & 2 & 0.45 & $<0.001$ \\
\hline Duration of admission & Control & 118 & 58.2 & 5 & 2 & 0.99 & \\
\hline Duration of re-admission & Intervention & 113 & 1 & 1 & 1 & 0 & - \\
\hline Duration of re-admission & Control & 118 & 1 & 1 & 1 & 0 & \\
\hline
\end{tabular}


Table 2. Comparison of fever and endomteritis in intervention and controls.

\begin{tabular}{|c|c|c|c|c|}
\hline Group & & No. & Percent & $P$ value \\
\hline \multirow[t]{5}{*}{ Control } & Afebrile, without endometritis & 83 & 70.3 & \multirow{10}{*}{$<0.001$} \\
\hline & Febrile, without endometritis & 23 & 19.5 & \\
\hline & Afebrile, with endometritis & 4 & 3.4 & \\
\hline & Febrile, with endometritis & 8 & 6.8 & \\
\hline & Total & 118 & 100 & \\
\hline \multirow[t]{5}{*}{ Intervention } & Afebrile, without endometritis & 105 & 92.9 & \\
\hline & Febrile, without endometritis & 3 & 2.7 & \\
\hline & Afebrile, with endometritis & 2 & 1.8 & \\
\hline & Febrile, with endometritis & 3 & 2.7 & \\
\hline & Total & 113 & 100 & \\
\hline
\end{tabular}

were $23(19.5 \%)$ and afebrile patients with endometritis were $4(3.4 \%)$ which is statistically significant $(\mathrm{P}<$ 0.001). Wound infection was not seen in intervention or control groups.

\section{Discussion}

Using antibiotics as prophylaxis is effective in decreasing post-cesarean infection and studies have shown that using antibiotics after cesarean can decrease infections and duration of hospital admission [27]. In current study average admission days in intervention group which had received prophylactic antibiotics (azithromycin, cefalexin and keflin) was significantly less than control group which received only keflin, which shows synergestic effect of two antibiotics (azithromycin and cefalexin) in decreasing duration of admission. A similar study on 386 women undergone cesarean section was performed to determine the efficacy of cefoxitin on prophylaxis of post surgical infection [28]. This study showed prophylaxis with cefoxitin does not decrease duration of admission significantly which is different from our study. According to our study, fever was less seen in intervention group and BMI of febrile patients was significantly higher (both in intervention and control groups) than afebrile patients. Endometritis after cesarean had no significant difference both in intervention and control groups. Both groups had no wound infection after cesarean.

In clinical trial using ampicillin alone in comparison with combination of ampicillin and gentamycin had increased risk of endometritis and fever and prolonged duration of admission [29]. Other clinical trials show that broad spectrum antibiotic regimens (such as limited spectrum antibiotics and other antibiotics such as azithromycin, gentamycin, and metronidazole) compared to other limited spectrum antibiotics are significantly effective in decreasing post-cesarean infection (30\% - 60\%) and decreasing duration of admission which are in favor of our study [30]-[32]. A 14-year cohort study in United States has confirmed that with increasing administration of broad spectrum antibiotic prophylaxis containing azithromycin, post-cesarean endometritis had decreased which is in contrast with our study [31].

A systematic review has shown that azithromycin is the best choice of second generation antibiotics for broad spectrum regimen in cesarean section. This antibiotic with long half life (68 hours) has higher tissue concentration and less potential of being transferred to fetus in comparison to other antibiotics. This antibiotic has also aerobic and anaerobic coverage, and reduces endometritis and wound infection significantly [32].

\section{Conclusion}

Regarding increased rate of obesity among adolescents and association of obesity with wound infection, concomitant use of a first generation cephalosporin (keflin in this study), azithromycin and cephalexin as prophylaxis reduces duration of admission and fever after cesarean section in comparison with first generation cephalosporin alone, so use of azithromycin as prophylaxis is recommended after cesarean to reduce infection and post surgical morbidity. 


\section{References}

[1] (2004) Antibiotic Prophylaxis for Surgery. Treatment Guidelines. The Medical Letter, 2, 27-32.

[2] Kirkland, K.B., Briggs, J.P., Trivette, S.L., Wilkinson, W.E. and Sexton, D.J. (1999) The Impact of Surgical Site Infections in the 1990s: Attributable Mortality, Excess Length of Hospitalization, and Extra Costs. Infection Control \& Hospital Epidemiology, 20, 725-730. http://dx.doi.org/10.1086/501572

[3] (1999) ASHP Therapeutic Guidelines on Antimicrobial Prophylaxis in Surgery. AJHP, 56, 1839-1887.

[4] Classen, D.C., Evans, R.S., Pestotnik, S.L., Horn, S.D., Menlove, R.L. and Burke, J.P. (1992) The Timing of Prophylactic Administration of Antibiotics and the Risk of Surgical-Wound Infection. New England Journal of Medicine, 326, 281-286. http://dx.doi.org/10.1056/NEJM199201303260501

[5] Mangram, A.J., Horan, T.C., Pearson, M.L., Silver, L.C. and Jarvis, W.R. (1999) Guideline for Prevention of Surgical Site Infection, 1999. Centers for Disease Control and Prevention (CDC) Hospital Infection Control Practices Advisory Committee. American Journal of Infection Control, 27, 97-132. http://dx.doi.org/10.1016/S0196-6553(99)70088-X

[6] American Society of Health System Pharmacists (1999) ASHP Therapeutic Guidelines on Antimicrobial Prophylaxis in Surgery. American Society of Health-System Pharmacists. American Journal of Health-System Pharmacy, 56, 18391888.

[7] Smaill, F. and Hofmeyr, G.J. (2002) Antibiotic Prophylaxis for Cesarean Section. Cochrane Database of Systematic Reviews, 2002, Article ID: CD000933.

[8] Centers for Medicare \& Medicaid Services (2008) Physician Quality Reporting Initiative (PQRI) Quality Measures Specifications. http://www.cms.hhs.gov/PQRI/downloads/2008PQRIMeasureSpecifications123107.pdf

[9] American College of Obstetricians and Gynecologists (2003) ACOG Practice Bulletin Number 47, October 2003: Prophylactic Antibiotics in Labor and Delivery. Obstetrics \& Gynecology, 102, 875-882. http://dx.doi.org/10.1016/S0029-7844(03)00984-0

[10] Martin, J.A., Hamilton, B.E., Sutton, P.D., et al. (2007) Births: Final Data for 2005. National Vital Statistics Reports, 56, 1-103.

[11] Hamilton, B.E., Martin, J.A. and Ventura, S.J. (2007) Births: Preliminary Data for 2006. National Vital Statistics Reports, 56, 1-18.

[12] MacDorman, M.F., Menacker, F. and Declercq, E. (2008) Cesarean Birth in the United States: Epidemiology, Trends, and Outcomes. Clinics in Perinatology, 35, 293-307. http://dx.doi.org/10.1016/j.clp.2008.03.007

[13] Bratzler, D.W. and Houck, P.M. (2005) Antimicrobial Prophylaxis for Surgery: An Advisory Statement from the National Surgical Infection Prevention Project. The American Journal of Surgery, 189, 395-404. http://dx.doi.org/10.1016/j.amjsurg.2005.01.015

[14] Surgical Infection Prevention Data (SIP) Florida Agency for Healthcare Administration (AHCA). http://ahca.myflorida.com

[15] United States Department of Health \& Human Services. HHS Hospital Compare: Information for Professionals. http://www.hospitalcompare.hhs.gov/

[16] Edwards, F.H., Engelman, R.M., Houck, P., Shahian, D.M. and Bridges, C.R. (2006) The Society of Thoracic Surgeons Practice Guideline Series: Antibiotic Prophylaxis in Cardiac Surgery, Part I: Duration. The Annals of Thoracic Surgery, 81, 397-404. http://dx.doi.org/10.1016/j.athoracsur.2005.06.034

[17] Fabian, T.C., Croce, M.A., Payne, L.W., Minard, G., Pritchard, F.E. and Kudsk, K.A. (1992) Duration of Antibiotic Therapy for Penetrating Abdominal Trauma: A Prospective Trial. Surgery, 112, 788-795.

[18] Pevzner, L., Swank, M., Krepel, C., Wing, D.A., Chan, K. and Edmiston Jr., C.E. (2011) Effects of Maternal Obesity on Tissue Concentrations of Prophylactic Cefazolin during Cesarean Delivery. Obstetrics \& Gynecology, 117, 877880.

[19] Bozorgzadeh, A., Pizzi, W.F., Barie, P.S., Khaneja, S.C., LaMaute, H.R., Mandava, N., et al. (1999) The Duration of Antibiotic Administration in Penetrating Abdominal Trauma. The American Journal of Surgery, 177, 125-131. http://dx.doi.org/10.1016/S0002-9610(98)00317-1

[20] Luchette, F.A., Borzotta, A.P., Croce, M.A., O’Neill, P.A., Whittmann, D.H., Whittmann, D.H., et al. (2006) Practice Management Guidelines for Prophylactic Antibiotic Use in Penetrating Abdominal Trauma. http://www.east.org

[21] Chang, W.T., Lee, K.T., Chuang, S.C., Wang, S.N., Kuo, K.K., Chen, J.S., et al. (2006) The Impact of Prophylactic Antibiotics on Postoperative Infection Complication in Elective Laparoscopic Cholecystectomy: A Prospective Randomized Study. The American Journal of Surgery, 191, 721-725. http://dx.doi.org/10.1016/j.amjsurg.2006.01.050

[22] Song, F. and Glenny, A.M. (1998) Antimicrobial Prophylaxis in Colorectal Surgery: A Systematic Review of Randomized Controlled Trials. British Journal of Surgery, 85, 1232-1241. 
http://dx.doi.org/10.1046/j.1365-2168.1998.00883.x

[23] Barie, P.S. (2002) Surgical Site Infections: Epidemiology and Prevention. Surgical Infections, 3, S9-S21. http://dx.doi.org/10.1089/sur.2002.3.s1-9

[24] Lewis, R.T., Goodall, R.G., Marien, B., Park, M., Lloyd-Smith, W. and Wiegand, F.M. (1991) Efficacy and Distribution of Single-Dose Preoperative Antibiotic Prophylaxis in High-Risk Gastroduodenal Surgery. Canadian Journal of Surgery, 34, 177-222.

[25] ACOG Committee on Practice Bulletins (2006) ACOG Practice Bulletin No. 74: Antibiotic Prophylaxis for Gynecologic Procedures. Obstetrics \& Gynecolog, 108, 225-234. http://dx.doi.org/10.1097/00006250-200607000-00057

[26] Stork, C.M. (2006) Antibiotics, Antifungals, and Antivirals. In Nelson, L.H., Flomenbaum, N., Goldfrank, L.R., Hoffman, R.L., Howland, M.D. and Lewin, N.A., Eds., Goldfrank’s Toxicologic Emergencies, McGraw-Hill, New York, 847.

[27] (1994) Antimicrobial Prophylaxis in Surgery (Clinical Practice Guidelines). Canadian Medical Association Journal, 151, 925-931.

[28] Harger, J.H. and English, D.H. (1981) Selection of Patients for Antibiotic Prophylaxis in Cesarean Sections. American Journal of Obstetrics \& Gynecology, 141, 752-758.

[29] O’Leary, J.A., Mullins Jr., J.H. and Andrinopoulos, G.C. (1986) Ampicillin vs. Ampicillin-Gentamicin Prophylaxis in High-Risk Primary Cesarean Section. Journal of Reproductive Medicine, 31, 27-30.

[30] Andrews, W.W., Hauth, J.C., Cliver, S.P., Savage, K. and Goldenberg, R.L. (2003) Randomized Clinical Trial of Extended Spectrum Antibiotic Prophylaxis with Coverage for Ureaplasma urealyticum to Reduce Post-Cesarean Delivery Endometritis. Obstetrics \& Gynecology, 101, 1183-1189. http://dx.doi.org/10.1016/S0029-7844(03)00016-4

[31] Tita, A.T., Hauth, J.C., Grimes, A., Owen, J., Stamm, A.M. and Andrews, W.W. (2008) Decreasing Incidence of PostCesarean Endometritis with Extended-Spectrum Antibiotic Prophylaxis. Obstetrics \& Gynecology, 111, 51-56. http://dx.doi.org/10.1097/01.AOG.0000295868.43851.39

[32] Tita, A., Rouse, D.J., Blackwell, S., Saade, G.R., Spong, C.Y. and Andrews, W.W. (2009) Evolving Concepts in Antibiotic Prophylaxis for Cesarean Delivery: A Systematic Review. Obstetrics \& Gynecology, 113, 675-682. http://dx.doi.org/10.1097/AOG.0b013e318197c3b6 
Scientific Research Publishing (SCIRP) is one of the largest Open Access journal publishers. It is currently publishing more than 200 open access, online, peer-reviewed journals covering a wide range of academic disciplines. SCIRP serves the worldwide academic communities and contributes to the progress and application of science with its publication.

Other selected journals from SCIRP are listed as below. Submit your manuscript to us via either submit@scirp.org or Online Submission Portal.

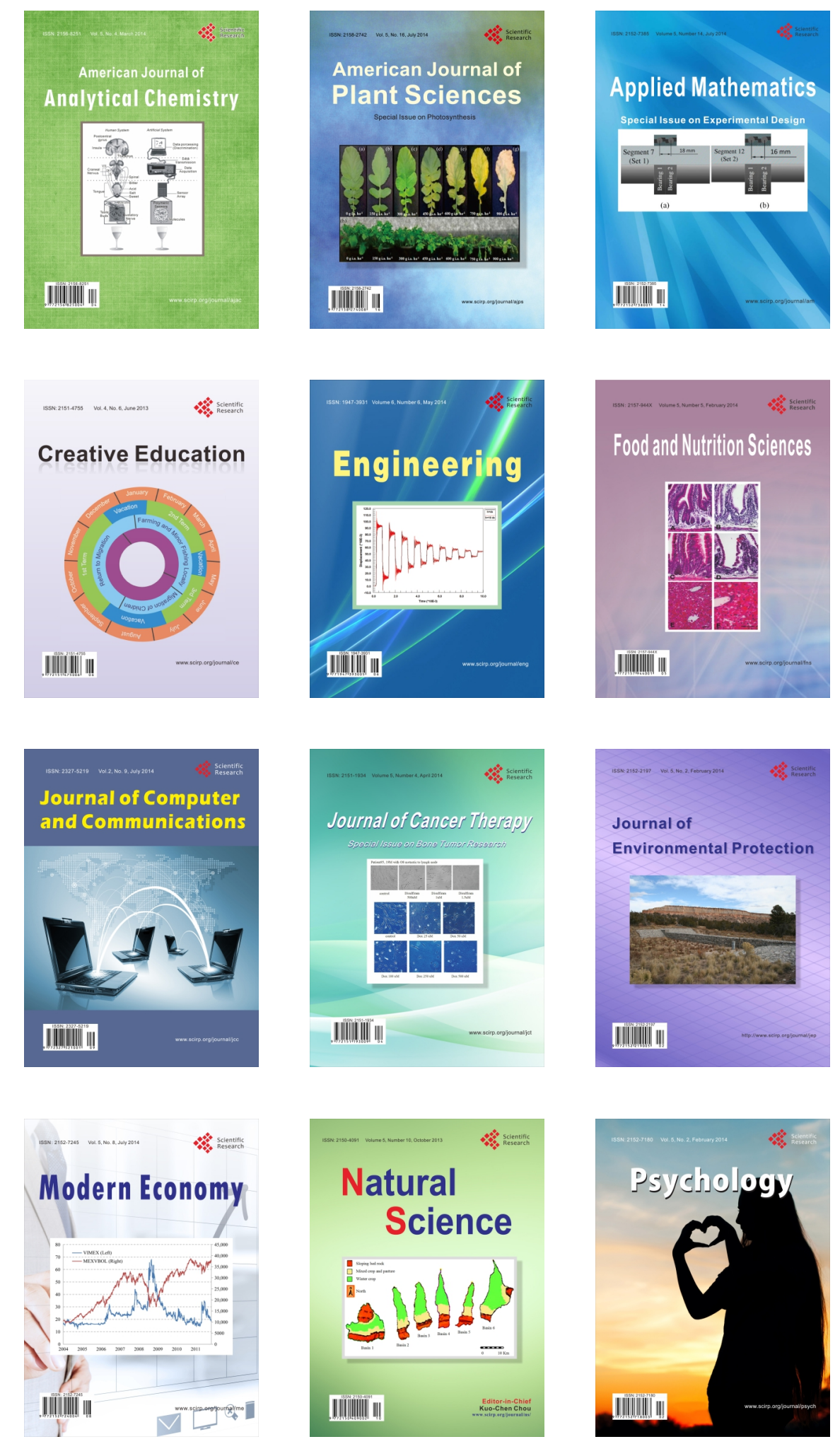